\title{
Applied art in the interaction with environmental architecture and urban environment
}

\author{
Lenh Hung Tu Do ${ }^{1,2, *}$ \\ ${ }^{1}$ Saigon University of Technology (STU), Faculty of Design, 180 Cao Lo street, Ward 4, District 8, \\ HCM City \\ ${ }^{2}$ HCMCity University of Architecture, 196 Pasteur, Ward 6, District 3, HCM City
}

\begin{abstract}
Applied art is the synthesis of many science and technologies, production process technology, and it has strong development in many countries all over the world. Applied art products are always present in all shapes and sizes in every urban space and have a strong interaction with the architectural and environmental landscape. A modern civilized city always needs harmonious alignment in the planning of these elements. In many urban areas in Vietnam, the interaction between architectural landscapes, urban environments, and urban beauties was not really taken seriously. It is obvious that the weaknesses in management are directly affecting the urban beauty. The overall picture of the city was not beautiful due to the absence of a head of the urban management. Discussing some solutions to improve the face of urban in Vietnam, it is necessary to clearly define the important role of the urban management levels; enhance the role of architects, artists, designers; build a civilized lifestyle, educate the sense of self-awareness and proper behavior of each urban resident.
\end{abstract}

\section{Introduction}

Applied arts an art form that combines art and function; pragmatics and beauty; durability and aesthetics. It is the sum of many branches such as science and technology, technological process of production and strong development in many countries in the world. Applied arts is most widely used in various types of art. Although applied arts covers a very wide range, but it has not been defined in the most general and accurate way. Nowadays there are so many different concepts and interpretations.

Increasingly affirming the essential role serving life and the people at all times and in all fields of applied arts including: Designing industrial products (jewelry decoration, gold, silver, gemstones, lacquer ware, wood products such as pottery, stone, bronze, plastic ware ...; decorative patterns for carpets...) and many industrial products designing such as televisions, refrigerators, cars, airplanes, trains, ships... are constantly changing and redesigning new styles to suit their needs and conditions as well as the development of modern science and technology; Fashion design (textiles, embroidery, lace...); Graphic design (packaging, decoration, advertising goods, printed graphics, newspapers, postage stamps, money...); Design stage art - cinema (context, costumes, props...); Interior and

\footnotetext{
* Corresponding author: dolenhhungtu@gmail.com
} 
exterior design (playing a key role in urban development when incorporating artist and architect to create the harmony of the overall urban architectural environment); The art of installation, public decoration is closely linked to: light designing, air designing, useful products designing from waste materials...

In every city all over the world, applied art products are always present in all shapes and sizes at everywhere in urban space and have closed interaction with architectural and environmental landscape: from signposts of each street; terminals, parking lots to public trash containers; from relaxing benches in parks to banners system, poster with pictures and commercials eye-catching outdoors; from the signposts of shops, supermarkets, eateries... to the flags, inscriptions, slogans in the daytime or in the festive occasions... So, along with monument system, statues... Outdoor art is obviously an indispensable element in urban art in general and has a closed and indispensable interaction with the architectural and environmental landscape in any city.

A modern, civilized city always needs the harmonious adjustment in a unified planning between architectural and environmental landscape. It is obviously that the environment, landscape architecture and applied art are three important elements that make up the caste and hallmarks of each modernity urban.

In the past, only the art of visual art including fine arts and sculpture (paintings, statues, reliefs) are noble while applied arts and handicraft art are considered despicable types. Even they are not arts. For years, the "shirt" of arts became increasingly cramped, and became small with its original conceptual boundaries. Modern cities also tolerate many other expression modes of postmodern art such as spray painting (pictures or text) on fence walls... are identified as Graffiti, Installation, Performance, Body art, Land art, Public art, Cinematism...blending, interacting and interwoven between different types of applied art to create a separate appearance for the city. Thus, type's identification of applied art in the living space of people can also be changed accordingly depending on the different approaches nowadays.

\section{Literature review}

The History of Design Book defines "applied arts" as "design, industrial design, product art, environmental design or object world design"[1]. According to the Wikipedia dictionary, "design" means "industrial arts", "industrial design" or "applied arts". Although it has been used since the 16th century in the UK for the design, fabrication and planning of industrial products, but only to the industrialization of the nineteenth century, the term fully understood as "industrial art" or "applied art. In Vietnam, this term was used in the 1960s, it came from Industrielle Formgestaltung (in German) and was translated as "Industrial Art" -nowadays, and this term became familiar industrial term.

In Article 15.2, the Decree of the Vietnamese Government 100/2006 / NĐ - CP (cited at Point g, Clause 1, Article 14 of the Law on Intellectual Property), specifies the notion of Applied Art: "Represented by lines, colors, shapes, and layouts with useful features that can be attached to a useful object, mass-produced by hand or by machine, such as: logo; handicrafts; form shown on the product; packaging products". Almost every object in our life is a product of applied art, and can "percepting the beauty of the visual senses as well as objects to use, so it belongs to the type of material and non-material art and culture" [2].

The "Environmental Art" format is "an overview including the linkage between arts, science, ecological environment, architecture, trees... to create that environment. This is the task of environmental art designers, architects, interior designers, sculptors... "[3]. In essence, it is just another way of applying art to "the environment in construction and real estate".

Landscape Architecture is a field of expertise that requires practical application of the principles of science, technology and arts, covering a wide range of disciplines such as spatial 
planning, technical infrastructure, architectural works, fine arts / applied arts (sculpture, painting,...) to directly affect to the management and conservation of human resources, natural resources and man-made constructions; to deal with the problems of organizing leisure and recreation environment; to build and renovate the environment, to organize architectural art in the interaction between nature and people and architectural works, both for the purpose of achieving fine, safe and enhance humans enjoyment. In fact, urban art is not a symbiosis element but an integral part of a harmonious whole and not only aesthetically pleasing to the architectural work, but also contributes to present civilization, high level of an urban space. The general tendency of many countries in the world, in line with the trend of the times, is increasing the application of art into architectural space.

As information and communication technology are expanding in modern urban space, applied art exhibits a strong interaction with them. There have been and will be new concepts emerging and people are more likely to find new meaningful names such as Visual Communication Design and when this mode of communication has been added sound, not just visual, has been outlined as Communication design [4]. Many researchers have predicted: "When the media is primarily based on audio-visual systems, on the radio, computers screen, and graphic designers also have to work on the computer to create $2 \mathrm{D}, 3 \mathrm{D}$, static and dynamic objects. They create new artwork applications much more effective than traditional graphic advertising and publishing" [1].

The standards that make up urban beauty always require the unity from master to detail. Applied arts in urban space exists through all visual effects from elements of advertising art (visual art, the meaning and many kinds of type, colors... eyes atraction, lively); Colors (the overall colors harmony of architechture, the building, the decorations, displaying shop, slogans, decals, trees, advertising lights, and lights night); Designs (Architechture: buildings, fountains..., construction works: bridges, poles, monuments, reliefs, decorative works, green trees, natural flowers); Lines (sensed through the overall visual effect between nature and artificial art decoration); Light (including natural light at moments of rain, sun, fog, early, noon, evening, dark, and lighting effects, advertising from artificial light sources); Water surface: (rivers, lakes, natural springs, fountains, artificial glass of artificial water...). According to architect (KTS) Nguyen Huy Phach, "the face of the city is a symphony of master planning, landscape architecture, environment and urban art in which applied art is an indispensable element..." [5].

\section{Aesthetic condition of some urban centers in Vietnam today}

There is no lack of beautiful city in Vietnam.

Hoi An ancient town is one of good example of the harmony between heritage values, preservation and promotion of material and spiritual values. It is the architectural space, landscape and artistic values of the river, the road, the type of house, the wall, the bridge, the patio, the sky well, the wall of vines... The applied art products with souvenirs, garments in the shops, shops with all kinds of lanterns were hang high, low... that create space of interior - exterior Asia. They have made the street look like an impressive light pearl, creating a great attraction too many visitors from domestic and all over the world. 


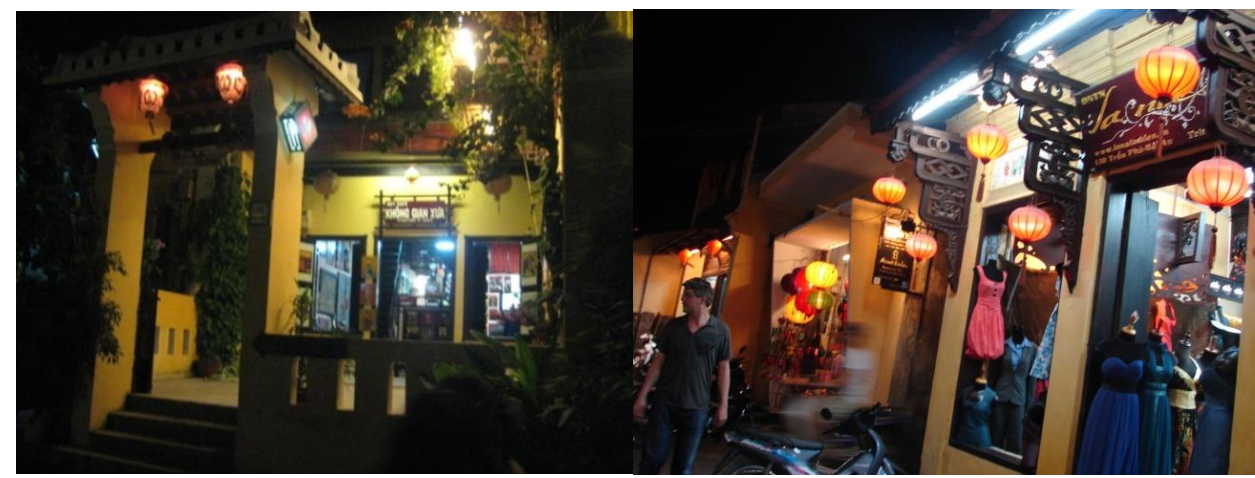

Fig. 1. Hoi An - ancient space (2015).

Phu My Hung new urban area, District 7 in Ho Chi Minh City is also a bright spot with the harmony between architectural space and common environment. With elegant color, luxury; a harmonious combination of public architecture and applied art products, Phu My Hung has become a modern urban area on a par with many countries in the region. It is creating a remarkable impression when matching with any neighborhood area in the city.

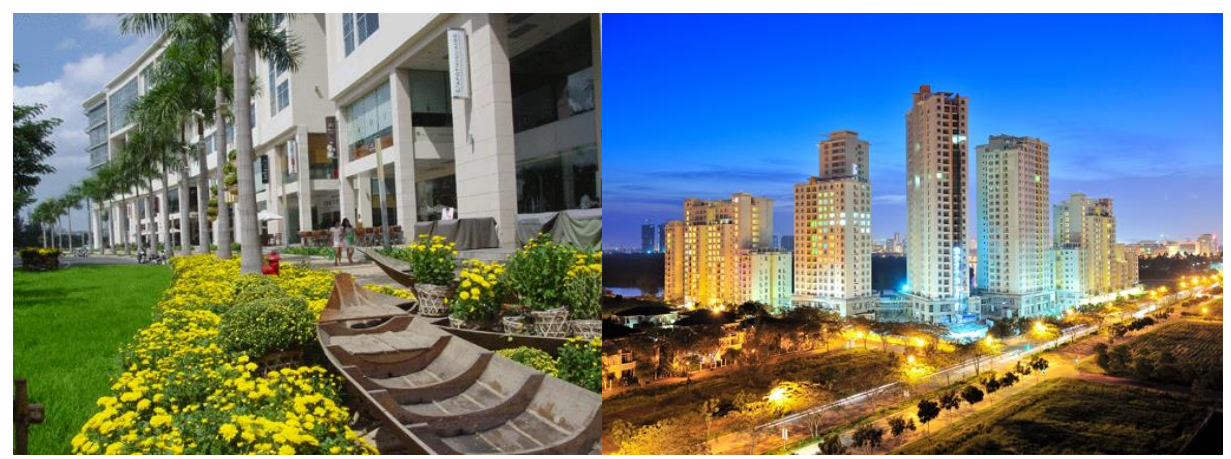

Fig. 2. Phu My Hung. Source: Internet.

However, in many Vietnamese urban, the interaction between architectural, environmental landscape and the arts of urban beautification are being not really taken seriously. "If local buildings are quite good, the combination of these structures in urban areas are often messy or unattractive. One of the main reasons for this situation is lack of planning and involvement of architectural landscape" [6].

The situation of building arbitrarily, unilaterally and unplanned that make the face of the city become poor, worn and shabby. There are a number of ultra-thin houses that have sprung up after the newly opened road. They have been launched through after clearance of the buildings which have left several square meters of ground. Except some villas or high-end apartments were built later, the rest are high buildings, low houses race to cramped together because of lack of overall planning. Sharp roofs, flat roofs, corrugated roofs... are filled with clutter. Colors, materials, architectural styles, construction scales... are all spontaneously painted, as a consequence of the disorganization that has been continues to exist in the city, creating many neighborhoods areas with non-consistency of visual style. Besides that, the building materials scattered, piled up in many streets, alleyways that are caused dirt and obstruct traffic also.

Inundation, causing flooding, traffic jams in many places, reducing the longevity of roads, bridges and sewers quickly damaged, degraded. Not only that, when the garbage dirt rises, permeate into the source of clean water, lead to the disease difficult to avoid. 
Not being beauty and insecure always hang overhead. The power poles must hang a lot of wire bundles, telephone wire, television cable... condemned to blame. Sometimes, the rope breaks down to the road. At many corners of the street, the signs and the advertising ribbons are still cluttered. The crossroads, trunks, columns, walls... were dirty drawing, many flyers are piled up and peeling off each other. In addition, the leaflets were littered around the road and disposed of by the road, both reflective the ugly appearance and unhygienic.

On the ground, the various excavations of the electricity and water industry have destroyed along the road. The rebuilding of the roads after dig of underground structures is often rather careless. This caused the surface to pinhole the "potholes", flooded with water and drift thin layers of sweeping up the surface, exposed the land and stone that were not compacted under the road surface.

Currently, with over 10 million people, Ho Chi Minh City has a rate of trees of just over 3 square meters per capita (it is too low when compared to Russia which has the rate of greenery is 15 square meters per capita and United States is 20 square meters per capita). Many parks, gardens, public spaces are occupied by street vendors, even homeless are also setting up tents, dormitories, cooking, bathing, laundry, clothes, blankets, curtains... just outside in the middle of the day. Many sleeping naked on the bench, wandering, dust, cigarettes, injecting drugs stealthily stealth under the bridge, corners hidden... made cultural and aesthetic of the city face increasingly deteriorated. The lack of self-awareness, unhygienic, throwing garbage, spitting indiscriminately, defecation in the wrong place... that cause pollute, destroy the living environment. Many canals, black holes, stinking, garbage, bottles, nylon bags, dead animals... were thrown around the public. They have made the city dirtier and messier.

With practical habits, many households find ways to race to the front for their small and medium business that makes the city more and more mixed. Most of the roads, alleyways... restaurant, coffee refreshing... includes many restaurants dark, damp, lack of hygiene that affects the urban beauty. According to preliminary statistics, there are over 45.000 small pubs in business in Ho Chi Minh City [7]. If, every day to eat at a restaurant, we must be under 130 years to reach the number of pubs, restaurants that are available.

\section{Recognizes a number of major causes}

Some of the major's influent to urban aesthetics that can be identified, including:

+ Many levels of urban management are confused by the factors that directly affect urban beauty: economy, integration and open culture and traditional culture, people's intellectuals so they adjust policies slowly.

+ The overall picture of the city is still not very good due to lack of master conductor and power of urban management.

+ Inadequate technical infrastructure has caused many problems: electricity, water, unprotected roads, underground systems, asymmetric sewers cause severe congestion and floods in many places, Dragging traffic jams, damaged buildings.

+Lacking identity of architectural style, patchwork grows out of control because of loosened management for long periods of time.

+ Many behaviors affect the urban beauty exited for too long time by default and become a living way of self-interest, lack of self-consciousness of a large part of urban residents.

\section{Discus about some solutions to improve the face of Vietnamese urban}

Firstly, it asserted the particularly important role of urban administrations. 
Managing a city is the same to managing a miniature country. The role of the management level throughout the impact of the state policy and the implementation of power of central and local governments need synchronism and consistency. This is the prerequisite to manage, improve the face of the city. When the leaders are "competent" and "mindful" of particular interest in urban aesthetics, they ready listen to and acknowledge constructive input from professionals; When integrity authorities at all levels agree to implement sanctions, strictly punish all acts that affected the aesthetic, urban civilized lifestyle as bad things in the status of Vietnamese urban that were mentioned above, the situation will be improved.

On planning management, there should be a comprehensive strategy ahead for years. Urban planners need a general and holistic view of the development and management of entire cities and regions. Measures should be taken to expand the urban area, expand the population from the central areas, prevent the residents from intermingling with the office, the high-class services coordinate, the traffic flow properly in order to solve traffic jams;

Regarding the construction management, strict compliance with construction planning, resolutely dismantling, smashing and illegally constructing works; Construction of underground works to reduce the load on open ground; To build works in synchronous manner with the system of signboards, guidance on parking places, entrances and ways; Do not let new buildings affect urban order, safety and aesthetics. The spontaneous architecture, people do it themselves, hybrid, patchwork, do not carry the identity is the "enemy" of urban beauty. The beauty lies in the scale of the overall science, resort space (park, artificial forest ...), community living space junction, large square can accommodate thousands of people, impressive monuments create impressive Strong vision contributes to the mark of the face of each city. It is necessary to assess the current status of the sculptures and to propose some feasible solutions to provide a theoretical and practical basis to assist the regulator in the planning and construction of structures. Sculpture is suitable for the current social development conditions [8]. When crowded urban centers tend to grow more and more taller to save land, the interactive mode of applied art needs to be treated differently from the city's periphery - where attention is always required to leave the natural space for each house that has garden, shady green trees...

On the management and protection of environmental resources, it is necessary to uphold the sense of preserving and protecting the nature; Create alternating in urban structures alongside buildings, fountains, creating more greenways, flower gardens, pure lakes, lawns, trees, leaves, flowers and fruit... and artificial forests as the lungs regulate the environment... in the regulation of behavior friendly to the natural environment.

Secondly, enhance the role of professionals: architects / art artists / designers

Architects, painters, sculptors, applied art designers... are the main force in organizing and implementing specific solutions for urban upgrading. However, "most of the major landscape architectural contracts are now available to foreign landscape consultants such as Deso Defrain, Souquet Associates (France), SWA and Sasaki Associates (USA) ..." [6], there are no outstanding Vietnamese landscape designer and because of their old-fashioned thinking. There is a need for group co-ordination among individuals, legal entities, and professional associations to combine the advantages of interdisciplinary - multidisciplinary, pooling more resources from experience, connecting the resonance of creativity from the many National and international experts in many fields. According to architect. Ngo Viet Nam Son and architect Nguyen Huu Thai, it is necessary to design and manage the use of outdoor space, including ground, water, space between buildings and small architectural works to increase the value for the landscape or create highlights; It is also necessary to study the design process from ideas to construction with reference to international experience, but must be appropriate to Vietnam's conditions.

Thirdly, summing up the aesthetic effects on the basis of increasing the content creation of art between applied art and modern technical equipment. 
Generally, the combination of architecture and fine arts is a necessary condition in the planning of urban construction and embellishment. These are clearly visible effects in the space of architectural landscapes and urban environment such as monument systems, statues, stadium, outdoor murals (usually placed in wide squares, Parks, flower gardens, intersections...); High-rise skyscrapers still need plenty of rooms for cool, clear air. Even when it is necessary to trim and prune high trees to avoid breaking down, entangled in electrical wires, dangerous when rain storms, and we should also consider the beauty of natural aesthetics. Design icons are set as accents, advertising signage system, flags, flowers, fanciful, propaganda, monolithic led displays, signposts, relaxing seats, trast buckets. On the streets, where the islands, bus stops, electricity poles, clocks, lights, public beacons at intersections... add more glamor to the cityscape.

The visual effect depends on material elements, designs, specialized color lamps and the art of lighting treatment when they take effective. In architectural decoration, light is one of the most important constituent elements. In the past, lighting was merely a function of lighting. Lighting gradually became more and more complete. Besides that, the digital technology of the digital age are grew more and more rapidly like storms, so light is no longer the same as before but became the art of visual application (also known as lighting art form). Colorful light, starting from the mediating role of harmony between architecture and the surrounding environment, has become an effective way to increase the visual effect. When the technical equipment is actively controlled to ensure the light intensity, limited shine, will create a high aesthetic effect, but also express the "soul" of the architecture being lighting and surrounding environment $[9,10]$.

In the landscape of urban environmental architecture, the harmony of nature between natural space and artifacts create different beauties of the city compared to other cities. According to Prof. Dr. Nguyen Minh Hoa, factors that bring aesthetic value to the city include: the principle of harmony; Symmetrical and asymmetrical; Aesthetics and aversion; Real and virtual; Shape and volume; Sounds and colors; Rhythm and tone; Past and present; Traditional and modern. Interactive relationships create beauty (or vice versa) for each major city are: Architecture, Planning, Building and it is unreasonable that applied art / fine arts stays out of these interactive relationships.

\section{Conclusions}

In fact, urban art is not a symbiosis element but an integral part of a harmonious whole and not only aesthetically pleasing to the architectural work, but also contributes to present civilization, high level of an urban space. The general tendency of many countries in the world, in line with the trend of the times, is increasing the application of art into architectural space.

In Vietnam, lacking of applied art works with aesthetical values and imprints, traditional characters that are placed in urban space.

While architecture is often associated with pragmatic values, which are more concerned with the use of both interior and exterior space, applied arts in urban areas tend to spiritual values. The organization of human habitat is aesthetically pleasing. When the technical and aesthetics are harmoniously combined, tight and constitutive in each other, united in one, will not only meet the needs of use but also satisfy the need to feel the aesthetics from the buildings. And the true durability of each architectural work has been and will be enhanced by the fact that it "bring on their back" the art values/ applied art. The material and spiritual values in urban space must satisfy the following factors: nature, history, geography, social status, economic circumstances, psychology and hobbies, customs and habits; Cultural practice of each ethnic group, thus urban art always bearing a deep impression of regional, regional, national and human characteristics. 
"The revolution 4.0 and Smart Cities" have been becoming an issue of the times for all humanity. It requires every manager, urban designer, or even every resident or visitor coming from a different location ... to have their own calculations and behaviors based on their own specific issues in order to build "specific smart urban strategies" that best meet population density, urban size, and "smart people" who can "Complicated to adapt to it"... [11].

Once the aesthetic consciousness, individual aesthetic thought are deeply promoted in the community and the encompasses a vast influence on the social life, the BEAUTY actually enters the throne.

\section{References}

1. Le Huy Van, Tran Van Binh, History of Design (Construction Publishing House, HN, 2003)

2. Government Decree No. 100/2006 / ND-CP (Article 15.2) cited at Point g, Clause 1, Article 14 of the Law on Intellectual Property

3. Le Ba Dung, www.Giaoducvn.vn/ Http://www.anvang.vn/zone/209/news/307-mythuat-ung-dung-trong-cuoc-song.aspx

4. N. H. N. Nguyen, Vietnamese Graphic Design in Relation to Traditional Art, PhD thesis (Vietnam National Academy of Arts and Culture, 2016)

5. H. P. Nguyen, http://baobacninh.com.vn/news_detail/90151/mot-vai-suy-nghi-ve-mythuat-voi-khong-gian-kien-truc-do-thi-bac-ninh.html

6. Ngo Viet Nam Son, Nguyen Huu Thai, Looking at the future of landscape architecture in Vietnam, Architecture Magazine, Vietnam Architects Association (2016)

7. X. T. Nguyen, Sculpture in Urban Culture in the South, Information and Communication Publishing House, doi.org/10.1051/e3sconf/20183303020 (2004)

8. M. H. Nguyen, Metropolitan Asia and HCMC (National University Publishing House, Ho Chi Minh, 2008)

9. M. H. Nguyen, Urbanism: Theoretical and Practical Issues (National University Publishing House, 2012)

10. Pho Duc Tung, Revolution 4.0 and Intelligent Urbanization - Practical implementation of intelligenturbanization in the world, Architectural Review (Vietnam Architects Association, 2017) 